\title{
Food Preservation: Traditional and Modern Techniques
}

\author{
Anil Kumar* \\ School of Biotechnology, Devi Ahilya University, Khandwa Road, Indore, India \\ *Corresponding Author: Anil Kumar, School of Biotechnology, Devi Ahilya University, Khandwa Road, Indore, India
}

Received: October 17, 2019; Published: November 05, 2019

DOI: 10.31080/ASNH.2019.03.0529

\begin{abstract}
In order to store the foodstuffs for a longer period without spoilage, proper preservation is important. However, preservative must not be toxic to human. There are techniques to eliminate microbial contamination and to avoid rancidity of fat. Care must also be taken to preserve nutritional value, texture and flavour of foodstuffs. In this mini-review, traditional techniques for preservation such as curing, freezing, canning, boiling, pickling and many more as well as modern techniques such as pasteurization, freeze drying, vacuum packing, irradiation, pascalization, biopreservation, hurdle technology and modified atmosphere are briefly discussed. Keywords: Pickling; Canning; Sugaring; Fermentation; Freeze Drying; Vacuum Packing; Biopreservation
\end{abstract}

\section{Introduction}

Food preservation is the process to handle and treat a food in order to control its spoilage by stopping the attack and growth of food borne diseases causing microbes; to avoid oxidation of fats (rancidity) and to maintain the nutritional value, texture and flavour of the food $[1,2]$.

It is well known that chemicals, microbes from the vicinity and enzymes present in the food itself may cause spoilage to food products. Besides, food and food products have to be transported from one place to another place. During transit, there are chances to deteriorate the food, loss or decrease in morphological attraction and reduction in nutritional value of the food. Therefore, it is important to do efforts for food preservation for longer shelf life, stability in quality, maintaining the morphological attraction and no change in taste [3].

Although many traditional methods used for food preservation, such as preservation of fruits by changing them into jams, had lower energy input and carbon footprint compared to modern techniques used. The traditional method involved boiling of fruits in order to kill microbes and to decrease the moisture contents, to add enough sugar in order to prevent re-growth of microbes and sealing in an air tight jar to prevent contamination. Sugaring causes the jam much hypertonic on which microbes are hard to survive [4; https://www.chelseagreen.com/product/fields-of-farmers/]. Some investigators have put a question mark on the current methods used for food preservation. In 2015, an International Agency for
Research on Cancer deputed by the WHO reported that processed meat which was processed by using salt, curing, fermentation and smoking got carcinogens in it (https://www.cancer.org/latestnews/world-health-organization-says-processed-meat-causescancer.html; https://www.iarc.fr/wp-content/uploads/2018/07/ pr240_E.pdf). Considering the importance of food preservation in order to reduce the chances of food poisoning and other diseases, here, various traditional as well as modern methods used for food preservation have been described.

\section{Traditional methods for food preservation}

The following are the main traditional methods for preservation of foods:

- Curing: The basic concept in curing of foods like meat, fishes and vegetables is to reduce the moisture contents by osmosis process. When moisture contents in any food are much low, there are much lesser chances of getting microbial infection and subsequently growth. Curing is also done for flavouring. It is done by adding salt, nitrates, sugar, nitrites in combinations which are capable of dehydrating the food. Higher salt used for curing also dehydrates bacteria resulting in their killing. Not only this, salt is also capable of slowing oxidation process resulting in slow oxidation of fat thus avoiding rancidity (https://en.wikipedia.org/wiki/ Food_preservation).

- $\quad$ Freezing: Freezing the food at temperatures ranging from minus $10^{\circ} \mathrm{C}$ to minus $80^{\circ} \mathrm{C}$ for long term storage is much 
common technique at the commercial scale as well as at homes. Under the freezing condition, microbes generally do not survive, and if any already existing microbe survived, it will not multiply. However, in case of hot served foods, it is always essential to heat the food above $75^{\circ} \mathrm{C}$ after bringing the food from freezer to room temperature. Almost in all the countries, cold stores are used for long term storage of fruits, vegetables and many other foodstuffs. There are processed foodstuffs like waffles from potato which are stored in a freezer but their raw material, potato tubers are stored at a temperature ranging from $0^{\circ} \mathrm{C}$ to $10^{\circ} \mathrm{C}$ in a cold room if storage has to be done for many months.

- Refrigeration: Refrigeration is considered to be artificial cooling to bring the temperature below room (ambient) temperature where heat is transferred from low temperature reservoir to high temperature reservoir either mechanically or electrically using laser or magnetically.

Processed and perishable foods are preserved traditionally by storing in a refrigerator. Generally, temperature in the refrigerator is maintained between $4{ }^{\circ} \mathrm{C}$ to $10^{\circ} \mathrm{C}$. At low temperature, mostly microbes do not grow and multiply or if grow, then at a much slower rate. In perishable foods where enzymes cause the rotting, these enzymes catalytic rate becomes much slower at low temperature. Although it has been observed that food may stay good in the refrigerator for a shorter period only (say for few hours or a day or so), however, refrigerator has proved good inside homes and in restaurants especially in summers. People in rural areas also use ice boxes with ice for cooling of the foodstuffs. Earlier or even today, some people also use root cellar for storage/ preservation of fruits, nuts and vegetables. Root cellar is an underground or partially underground structure and it is synonym of root crops which are stored in underground cellar. In root cellar, depending upon the foodstuff, storage can be done for weeks [5; https://en.wikipedia.org/ wiki/Refrigeration; https://www.chelseagreen.com/product/fields-of-farmers/].

- Boiling: It is a traditional way especially in developing countries to boil water in order to kill microbes if any in it, and thereafter, it is cooled to room temperature before drinking. It is also customary to boil milk before drinking (even pasteurized milk) in order to kill the microbes if any.

- Sugaring: It is customary even today to preserve certain foodstuffs using sugar as a preservative. The basic mode of action is that high sugar contents make the foodstuff hypertonic and microbes do not survive in hypertonic solution since hypertonic solution will draw water from the microbe and it will become dehydrated. It is quite common to store fruits in honey or sugar. Jams and jellies are also examples of sugaring. Many soft drinks concentrates like orange squash which have much sugar amount are also prepared based on this principle.

- Pickling: There are many customary ways including immersing foodstuff in vinegar or vegetable oil, or anaerobic fermentation by which lifespan of foods is increased and this process is called as pickling. This method changes the texture, flavour and taste of the food and preserved stuff is generally called as pickle. Pickle of many vegetables including carrot, cauliflower, lemon and of raw mangoes is much used in Asian countries including India. In many European countries, Canada and USA, pickles of eggs, fish and meat among others are eaten. Anaerobic fermentation (storing in vinegar) of vegetables and fruits such as mangoes, radish and carrots is also commonly used in Asian countries. Under fermentation conditions, there is production of organic acids like lactic acid, acetic acid which act as preservative agents. In some countries, brine (high salt) is also used for preservation. Under the conditions, there is killing of bacteria and other microbes (https://en.wikipedia.org/wiki/ Pickling).

- Canning: The process of canning for extending the shelf life of foodstuffs was discovered by Nicolas Appert, a French confectioner in early nineteenth century. The process involves cooking of the food, and thereafter sealing it in sterilized jars or cans, and boiling the containers for sterilization. Under the conditions, there is killing or weakening of any remaining microbe. The process could not be popular until 1864 when Louis Pasteur showed the relationship between the food spoilage and microbes, and subsequently illness [6; https://nchfp. uga.edu/publications/nchfp/factsheets/food_pres_hist.html].

It has been shown that different foodstuffs have natural protection against spoilage, however to different degrees. High acid foodstuffs such as strawberries do not need any preservative for canning and only boiling for a little time is sufficient. On the other hand, many other foodstuffs such as carrots need longer boiling and one has to add acidic preservative such as citric acid. Foodstuffs with low acid constituents such as vegetables and meats need pressure canning. However, canned foodstuffs are spoiled within a short span of time after opening the can or bottle.

Sometimes, can with canned food gets swollen or bursts due to gas production inside since canned foods are prone to entrance of water or microbes which help in decomposition of food. There are reports that canned food contained anaerobic microbe, Clostridium botulinum which produces a toxin capable of causing food poisoning or even sometimes death upon consumption by humans. The contamination of this microbe is generally not visible by naked eye, however, its toxin can be denatured by proper cooking. The Staphylococcus aureus con- 
tamination is also much common in canned mushrooms. This microbe also produces a toxin, however unlike toxin produced by Clostridium botulinum, this is not inactivated by heating the canned food (https://en.wikipedia.org/wiki/Canning).

- Fermentation: Certain foodstuffs such as beer, wine and cheese are manufactured by the process of fermentation using specific microbes. These fermentative microbes protect the foodstuff against other pathogenic microbes by producing an acid or alcohol which is toxic to other pathogenic microbes. During fermentation, controlled conditions such as salt, temperature, oxygen level and other parameters are maintained which help the fermentative microbe to produce the food product good enough for human consumption [6; https:// en.wikipedia.org/wiki/Fermentation_in_food_processing].

\section{Modern methods for food preservation}

The following are the main modern methods for preservation of foods:

\section{Pasteurization}

Even today, traditional way of heating a foodstuff to a temperature capable of killing microbes is used. In the market, milk is generally sold in sealed packets or jars after pasteurization. In homes, it is common especially in Asian countries including India to boil milk in order to kill microbe(s), if any, and thereafter, it is stored in a refrigerator

\section{Freeze drying}

This is one of the modern techniques where moisture contents from the foodstuff are removed at much lower temperature under frozen conditions using vacuum. The basic principle applied is to evaporate solid water (ice) by sublimation at lower pressure. It results in a foodstuff of high quality. Under the conditions, there is no change in the shape of the foodstuff. This technique is used in food processing and preservation of coffee. Vacuum drying is also used for long term storage of bacteria and yeasts [7-10].

\section{Vacuum packing}

In this technique, foodstuff is put in a plastic film bag and vacuum is created inside the bag by sucking air using a vacuum pump before sealing the bag. Under the conditions, microbes do not grow since they require oxygen for survival. This technique is mostly used for packing nuts since it keeps them fresh without losing flavour from oxidation [11; https://en.wikipedia.org/wiki/Vacuum_ packing]

\section{Irradiation}

Foodstuff is exposed to ionizing radiation either as $\beta$ - particles or $\gamma$ - rays. The radiation is capable of killing bacteria, molds and pests among others. The irradiation is also capable of decreasing the ripening of fruits and stops spoilage. Although, World Health
Organization (WHO) and Food and Agricultural Organization (FAO) have affirmed food irradiation, but there are controversies in this technique. Some people have a misconception that upon irradiation, food may become radioactive. Others oppose this technique by saying that irradiation may sterilize contaminated food [12-15; https://en.wikipedia.org/wiki/Food_irradiation]. This technique has been mostly used for spices, condiments and fresh fruits.

\section{Chemical food preservatives}

In processed foods, anti-microbial chemical agents are added to preserve them. These agents are added in smaller amount since these are mostly toxic when consumed in larger amount. Common preservatives are benzoic acid and benzoates which are used in acidic foods such as jams, salad dressing, juices, pickles, carbonated drinks, soy sauce among others. Sorbic acid and sorbates are used as preservatives in cheese, wine and baked foods among others. Nitrites and nitrates are used as preservatives in meats to prevent botulism toxin. Sulphur dioxide and sulphites are used in fruits and wine. Similarly, propionic acid and propionates are used in baked foods (https://en.wikipedia.org/wiki/Preservative).

\section{Pascalization}

In this technique, foodstuff is pressed inside a vessel exerting very high pressure to the tune of 70,000 lb per square inch. This technique is good since foodstuffs retain their freshness, flavour, texture and nutrients with destruction of microbes. Following this technique, there is much slower rate of spoilage of foodstuffs. This technique has been used for orange juice, guacamole and deli meats (https://en.wikipedia.org/wiki/Pascalization).

\section{Biopreservation}

When natural microbes or antimicrobials are used for preservation and increasing the shelf life of foodstuffs, it is called biopreservation. Here, generally either beneficial bacteria or fermentation products are used for controlling the spoilage and to inactivate pathogenic microbes, if present in the foodstuff $[16,17]$. Lactic acid bacteria have been used as biopreservatives. These bacteria produce lactic acid, acetic acid, bacteriocins and hydrogen peroxide among others which act as antimicrobials.

Horie., et al. [18] studied the importance of lactic acid bacteria and component change during fermentation of Ishizuchi-kurocha, a post-fermented tea used in Japan. The leaves of this tea are first fermented aerobically by fungi and thereafter anaerobically using lactic acid bacteria. They studied Lactobacillus plantarum subsp. plantarum isolated as the dominant species in Ishizuchi-kurocha. The component analysis showed that level of catechins, amino acids and $\gamma$-amino butyric acid in tea leaves changed during anaerobic fermentation. They showed that growth of Lactobacillus plantarum subsp. Plantarum and Lactobacillus brevis is important for taste and flavour. 
D'Amico de Alcântara., et al. [19] demonstrated antibacterial activity of Lactobacillus rhamnosus against Pseudomonas fluorescens and Pseudomonas putida both isolated from refrigerated raw milk. The anti-bacterial activity was due to production of organic acids. They showed that antibacterial activity of Lactobacillus rhamnosus can be exploited to improve quality of raw milk.

\section{Hurdle technology}

In this technology, more than one approach are applied to inactivate any pathogenic microbe, if present in a foodstuff. It is considered that these approaches act as hurdles for the microbes. It is important to select correct combination of approaches for effective food preservation. Leistner [20] defined hurdle technology as an intelligent combination of hurdles that secures the safety from microbes and ensures no loss of nutritional quality and economic viability of foodstuffs. Besides, these hurdles also don't change the smell, look and texture of the foodstuff. The main approaches used in hurdle technology are higher temperature during processing, increasing acidity, lowering redox potential, presence of preservatives and lower temperature for storage. Lactic acid bacteriocins have also been used in combination with other approaches to control the spoilage [16]. The intensity of these approaches is decided based on the nature of probable pathogen(s) in the foodstuff.

\section{Nonthermal plasma}

In this technology, surface of the foodstuff is exposed to a flame of ionized gas molecules such as nitrogen and helium. It helps in killing the microbes if present on the surface of the foodstuff (https://en.wikipedia.org/wiki/Food_preservation).

\section{Modified atmosphere}

In this approach, atmosphere in the surrounding of foodstuff is altered. Salad crops are packed in sealed bags where concentration of carbon dioxide is increased and of oxygen is reduced. However, under the conditions, there are chances of changing some nutrients such as vitamins. Grains are preserved using carbon dioxide. Some people put a block of dry ice (solid carbon dioxide) in the bottom of the container. Another way is by purging the container at the bottom by carbon dioxide. Generally, a cylinder of carbon dioxide can be used. Carbon dioxide prevents insects, molds and oxidation from damaging the grains. Nitrogen gas is also used to preserve grains. It is also capable of killing insects $[21,22]$.

For storage of larger quantities of foodstuffs, Controlled Atmospheric Storage (CAS) is used which is a sealed room where oxygen levels are reduced by infusing nitrogen gas. In air, on an average, oxygen is $21 \%$ whereas in such facilities, oxygen level is reduced to 1 to $2 \%$. The temperature is put between 0 to $2^{\circ} \mathrm{C}$ and humidity nearly $95 \%$. Level of carbon dioxide is also controlled in the room. In fact, all these atmospheric conditions are set according to nature of the foodstuff. Nowadays, atmospheric conditions in CAS are controlled with the help of computers.
There is a concept of air tight storage of foodstuffs especially of grains which is also called hermetic storage. In this storage, it is considered that as a result of respiration of grains, insects and fungi, there are changes in the enclosed atmosphere which help in controlling insect pests. It depends on the proper sealing, moisture contents in grains and temperature among others [23]

Martindale and Sciebel [24] correlated between food preservation and food waste and showed that proper food preservation will reduce wastage of food and suggested that it may solve the meal requirement in developing countries. They studied the frozen foods and fresh foods using Austrian marketplace and showed about six fold reduction in wastage upon emphasis on frozen food.

Agugo., et al. [25] studied the nutritional, sensory and storage aspects of mungbean substituted garri prepared in 30\%, 40\%, 50\% and $60 \%$ proportions for addition in ready to eat diet. They stored a sample of mungbean garri having 30\% mungbean and $70 \%$ garri in different packaging materials namely polythene bag, sac bag and plastic container on shelf and also inside the cupboard for four weeks. They observed lower microbial growth in mungbean garri sample packaged in sac bag and stored on the shelf during first and second week of storage. However, samples in plastic container stored in the cupboard showed lowest microbial growth during third and fourth week of storage. On the basis of observation about microbial growth, they concluded that substituted mungbean garri having 30 to $70 \%$ ratio of mungbean and garri was better storage wise as well as nutritionally for a feeding trial involving school children.

\section{Conclusion}

Considering food borne diseases due to consumption of spoiled food, proper preservation of foodstuffs is very important. Although, there are many existing techniques used for food preservation, considering the economic viability and social responsibility, more effective and safer techniques must be searched. There is much scope of food preservation including packaging commercially. More research must be carried out in this direction.

\section{Acknowledgements}

Author acknowledges the facilities of the Department of Biotechnology, Ministry of Science and Technology, Government of India, New Delhi (DBT) under the Bioinformatics Sub Centre as well as M.Sc. Biotechnology program used in the present work.

\section{Bibliography}

1. Lianou A., et al. "Microbiological spoilage of foods and beverages". In The Stability and Shelf Life of Food. (Subramanian, P. ed.) Second Edition Woodhead Publishing, India (2016): 3-42.

2. Sancho-Madriz MF. "Preservation of Food". In Encyclopedia of Food Sciences and Nutrition (Ed. Caballero, B.), IInd Edition, Elsevier Science Ltd Publisher (2003). 
3. Sharif ZIM., et al. "Review on methods for preservation and natural preservatives for extending the food longevity". Chemical Engineering Research Bulletin 19 (2017): 145-153.

4. Salatin J. Fields of Farmers: Interning, Mentoring, Partnering, Germinating, Chelesea Green Publishing, USA (2013).

5. Bubel M and Bubel N. Root Cellaring: Natural Cold Storage of Fruits and Vegetables. Storey Publishing, LLC, USA (1991).

6. Nummer BA. "Historical origins of food preservation". National Center for Home Food Preservation (2002).

7. Ratti C. "Hot air and freeze-drying of high-value foods: a review". Journal of Food Engineering 49 (2001): 311-319.

8. Ratti C. Advances in Food Dehydration. CRC Press (2019).

9. Fellows PJ. Freeze drying and freeze concentration". In Food Processing Technology: Principles and Practices, 4th Edition, Woodhead Publishing/ Elsevier Science (2017): 929-940.

10. Prosapio V., et al. "Optimization of freeze drying using a life cycle assessment approach: Strawberries' case study”. Journal of Cleaner Production 168 (2017): 1171-1179.

11. Perdue R. "Vacuum packaging". In The Wiley Encyclopedia of Packaging Technology (Editor: Yam, K. L). (2009).

12. World Health Organization. Wholesomeness of irradiated food. Geneva, Technical Report Series No. 659 (1981).

13. World Health Organization. High-Dose Irradiation: Wholesomeness of food irradiated with doses above $10 \mathrm{kGy}$. Report of a Joint FAO/IAEA/WHO Study Group. Geneva, Switzerland: World Health Organization; 1999. WHO Technical Report Series No. 890 (1999).

14. Conley ST. "What do consumers think about irradiated foods?" FSIS Food Safety Review (1992): 11-15.

15. Hauter W and Worth M. Zapped! Irradiation and the Death of Food, Food and Water Watch Press, Washington DC (2008).

16. Ananou S., et al. "Biopreservation, an ecological approach to improve the safety and shelf life of foods". In Communicating Current Research and Educational Topics and Trends in Applied Microbiology, Formatex (Ed. A. Mendez-Vilas) (2007): 475-486.

17. Yousef $\mathrm{AE}$ and Carolyn Carlstrom C. "Food Microbiology: A Laboratory Manual”. Wiley publishers (2003): 226.

18. Horie M., et al. "Evaluation of lactic acid bacteria and component change during fermentation of Ishizuchi-kurocha". Journal of Food Processing Preservation 43 (2019): e14186.
19. D’Amico de Alcântara AL., et al. "Antimicrobial activity of Lactobacillus rhamnosus against Pseudomonas fluorescens and Pseudomonas putida from raw milk". Journal of Food Processing and Preservation 43 (2019): e14082.

20. Leistner I. "Basic aspects of food preservation by hurdle technology". International Journal of Food Microbiology 55 (2000): 181-186

21. Annis PC and Dowsett HA. "Low oxygen disinfestation of grain: exposure periods needed for high mortality". Proc. International Conference on Controlled Atmosphere and Fumigation. Winnipeg, June 1992, Caspit Press, Jerusalem (1993): 71-83.

22. Annis PC and Morton R. "The acute mortality effects of carbon dioxide on various life stages of Sitophilus oryzae". Journal of Stored Products Research 33 (1997): 115-124

23. Annis PC and Banks HJ. "Is hermetic storage of grains feasible in modern agricultural systems?" In "Pest control and sustainable agriculture" (Eds. Corey, S.A., Dall, D.J. and Milne, W.M.). Publisher CSIRO, Australia (1993): 479-482.

24. Martindale W and Schiebel W. "The impact of food preservation on food waste". British Food Journal 119 (2017): 25102518 .

25. Agugo UA., et al. "Investigating the nutritional, sensory and storage qualities of substituted mungbean-garri diets". Journal of Food Technology and Preservation 3 (2019): 1-4.

Volume 3 Issue 12 December 2019 (C) All rights are reserved by Anil Kumar. 